Conclusions Through partnership working, the programme team were able to reach more people and influence the care that is being delivered to people living with a terminal illness in their own homes and in care homes in Lothian. The impact of this education initiative has resulted in ongoing relationships between all organisations involved.

\section{P-269 ABC 4 LD}

${ }^{1}$ Karenann Spicer, ${ }^{2}$ Helen Miller, ${ }^{3}$ Louise Jenkins. ${ }^{1}$ The Hospice of St Francis, Berkhamsted, UK; ${ }^{2}$ sabel Hospice, Welwyn Garden City, UK; ${ }^{3}$ Farnham House, Stevenage, UK

\subsection{6/bmispcare-2017-hospice.294}

Background Evidence demonstrates that professionals working with people with learning disabilities, report inadequate knowledge of good end of life care (Bekkema et al., 2014; Wiese et al., 2013; Ryan et al., 2011). Specifically, advance discussion about death and individuals' preferences (TuffreyWijne et al., 2013; Wagemans et al., 2013), breaking significant news (Wagemans et al., 2013) and communicating directly with the person with learning disabilities to make end of life decisions (Ryan et al., 2011) rather than deferring to professionals or carers (MacHale et al., 2009) present challenges for staff. Furthermore, staff highlight difficulties in supporting people with learning disabilities and their families through the end of life process (Todd, 2013) and supporting those around them after the person with learning disabilities has died.

Aim To enhance palliative care knowledge and skills for staff working with people with learning disabilities.

Method A six organisation collaborative completed a funded pilot Palliative Care Education Programme for two supported living homes for adults with learning disabilities. The programme was delivered by two hospice educators with support from Learning Disability community nurses and respective Palliative Care CNSs for the two and a half day face-to-face programme. The focus was to equip staff to deliver end of life care based on the hospice model to service users in their home setting. The programme was completed over three months following a pre-audit and preparation period. The $\mathrm{ABC} 4 \mathrm{LD}$ programme comprised of six modules from the original $\mathrm{EOE} \mathrm{ABC}$ education programme and was adapted to incorporate a half day managing complex grief and staff resilience.

Conclusions The outcomes of the training have been positive with 46 staff completing the training which has highlighted the gap of knowledge in terms of palliative care and meeting the needs of those adults with learning disabilities. The intention is to roll out a wider programme of training across Hertfordshire to replicate the learning and increase awareness for both palliative care and learning disability services.

\section{P-270 IMPROVING EOLC AT HOME PROVIDED BY DOMICILIARY TEAMS USING THE GSF DOMICILIARY CARE PROGRAMME}

Keri Thomas, Lucy Giles, Margaret Stobbart-Rowlands, Anne Keating. Gold Standards Framework Centre C.I.C. Shrewsbury, UK

10.1136/bmjspcare-2017-hospice.295

Aim Domiciliary care workers play an important but often unrecognised role in supporting people to remain at home as they near the end of life, especially those with dementia and frailty. Despite this, few receive specific training in end of life care. Focussed training enables home care workers to improve the quality of care for such people working with primary care, and contribute to better co-ordinated cross boundary care.

Method The GSF Domiciliary Care training programme in End of Life Care focuses on enabling generalist frontline staff in end of life competencies. The Train-the-Trainer cascade programme works with domiciliary care agency trainers using action- based, interactive learning and reflective practice in six modules, with virtual learning Zone/DVD, and resources. Comparative before and after qualitative and quantitative evaluation is intrinsic. We present an evaluation of progress of several teams using GSF training in end of life care, some delivered by hospices.

Results Homecare workers in various areas of the country show improvements in:

- Confidence and competence of home care staff

- Communication, working relationships and collaboration with primary care

- More Advance Care Planning discussions, with service users keen to be involved in these discussions

- Encouragement and empowerment of staff to advocate for their service users leading to improved communications with other professionals

- Increased awareness of the knowledge they already possessed and future training needs.

Conclusion This highlights the important role that domiciliary care workers play, and the importance of empowering care staff who interact with the service users on a daily basis. The GSF Domiciliary Care Training Programme boosts the confidence and competence of care workers, improves collaboration and coordination with others and helps to improve care for more people nearing the end of life at home - which is for most the best place to be.

\section{P-271 IS PROACTIVE PRIMARY END OF LIFE CARE POSSIBLE AND SUSTAINABLE?}

${ }^{1}$ Keri Thomas, ${ }^{2}$ Collette Clifford, 'Julie Armstrong Wilson. 'Gold Standards Framework Centre C.I.C. Shrewsbury, UK; ${ }^{2}$ University of Birmingham, Birmingham, UK

10.1136/bmjspcare-2017-hospice.296 
Aim Crises are frightening especially near the end of life. Primary care teams are pivotal in caring for patients in the final years of life, enabling more to live well and die where they choose, and reduce inappropriate crises and hospitalisation. With increasing pressures from the ageing population, rising mortality and limited resources, a more proactive approach to meeting these challenges is required.

The Gold Standards Framework (GSF) Quality Improvement Programme has been influential in EOLC since 2000 with most UK general practitioners using GSF foundation principles. We report on the findings of the first 17 GP practices undertaking GSF Going for Gold training and accreditation with some reaccredited three years later, demonstrating what is possible to achieve.

Method Primary care teams undertake a practice-based distance-learning GSF Gold programme with optional interactive workshops over 6-12 months. Evaluations before and after in preparation for accreditation include key outcome ratios, online After Death Analysis plus submission of a portfolio of evidence and assessment interview.

Results Cumulated findings for the accredited practices show significant improvements, including some reaccredited three years later demonstrating long-term sustainability. Practices demonstrate enhanced proactive end-of-life care, with earlier identification of over $60 \%$ of their patients who died, offering ACP discussions to over $65 \%$, leading to more home deaths and improved outcomes for patients and carers.

Conclusion Improving care for people in their last year of life in GP Practices with proactive person-centred care is pivotal to meeting the challenges of the ageing population, and making best use of limited resources. The GSF Gold programme reported here, is an example of a practical, well-received evidence-based quality improvement, leading to more proactive planned care in line with peoples' preferences, meeting the increasing needs of the ageing population.

\section{P-272 SUCCESSFUL SHARING OF MEDICAL EXPERTISE}

1,2Debbie Talbot, ${ }^{1,2}$ Sarah Mimmack. 'Birmingham St Mary's Hospice, Birmingham, UK; ${ }^{2} J o h n$ Taylor Hospice, Birmingham, UK

10.1136/bmispcare-2017-hospice.297

Background Two hospice organisations, serving the majority of the population of a major UK city (Hospice A and B). Hospice $B$ has been unsuccessful over several years, at recruiting into a substantive Consultant role. Medical staffing, was therefore identified as a potential area for joint working, that would improve patient experience and promote collaboration.

Aim Both organisations agreed that the Medical Director at Hospice A, would provide some clinical leadership to Hospice B.

Methods Medical Director job plan split between the two units (with backfill funded by Hospice B)

Initial objectives agreed:

- Review existing medical staffing and make recommendations around future workforce planning, including how to optimise chances of recruitment into consultant post(s)

- Identify opportunities for the hospices to work together more, especially around shared job roles and clinical redesign projects

- Lead a joint hospice initiative, to effect system -wide change for EOLC across the city.
Achievement against these objectives will be assessed at appraisal.

Results Recommendations around Hospice B medical staffing, included formally linking the Consultant post with Hospice A, making optimal use of peer support and existing CPD opportunities. Consultant body agreed to amalgamate second on-call services, for more efficient out of hours working. Revised job description approved by RCP - recruitment pending. Joint clinical working provoked wider sharing of resources such as policies, guidelines, education material etc and heightened efficiency around clinical governance. Both organisations are now scoping joint working around support functions such as IT. Combined senior clinical staff away day, identified priorities for influencing at regional and national level. Future EOLC stakeholder events scheduled.

Conclusions Good example of a joint clinical role, becoming a conduit for greater cooperation between neighbouring organisations. There have been benefits to both, including reputational. Most notably, however, patient care has been positively impacted, with less staff time being expended on duplicating efforts.

\section{P-273 MORE EFFECTIVE TOGETHER: PUTTING OUR HEADS TOGETHER TO INNOVATE AND LEAD}

Karen Causton, Nicola Button, Laura Shukla, Kathryn Davies. St Helena Hospice, Colchester, UK

\subsection{6/bmjspcare-2017-hospice.298}

Background The clinical heads of departments within our hospice had traditionally been located with their own teams, working in relative isolation. Budgets were managed individually, and often relatively small amounts of money were left unutilised. Clinical Heads did not always have a business background or expertise in this area.

Aims To share best practice, move away from silo working, utilise resources and encourage greater collaboration between the departmental heads.

Approach Help the Hospices' (2013) 'Future ambitions for hospice care; our mission and our opportunity' document recommends that hospices will be stronger in the future if attention is given to succession planning and developing leaders for the future. Furthermore, Hospice UK (2017) recommends that best practice is valued and shared, by combining expertise with business intelligence. One of the identified ways to achieve this, was to relocate the clinical heads of departments into an office together where they were joined by the newly appointed Head of Business, to facilitate coordinated working across teams. Positive feedback from members of our respective teams, our directors and visiting clinical heads from other hospices, has led us to believe that the approach is an innovative one.

Outcomes Joining the forces of clinical expertise and business acumen has provided collaborative leadership across Patient and Family Services and has generated the following benefits: joint strategic planning, inter-departmental budget setting, sharing of resources, joint KPI setting and performance monitoring. An example of this, is that combining left-over budgets from the three teams, which would otherwise have been left unspent, allowed a social worker to be employed to work across the organisation. 